\title{
JURISPRUDENCIA CONSTITUCIONAL DE LA SUPREMA CORTE DE JUSTICIA DE MÉXICO EN EL 2020
}

\author{
Constitutional jurisprudence of the Supreme \\ Court of Justice of Mexico in 2020 \\ ALFONSO HERRERA GARCÍA' \\ Universidad Panamericana \\ jaherrerag@yahoo.com.mx
}

Cómo citar/Citation

Herrera García, A. (2021).

Jurisprudencia constitucional de la Suprema Corte de Justicia de México en el 2020.

Anuario Iberoamericano de Justicia Constitucional, 25(2), 607-620.

doi: https://doi.org/10.18042/cepc/aijc.25.21

\section{SUMARIO}

I. INTRODUCCIÓN. II. IMPLEMENTACIÓN DEL DERECHO INTERNACIONAL DE LOS DERECHOS HUMANOS: 1. Recepción jurisdiccional del caso García Cruz y Sánchez Silvestre vs. México. 2. Derecho convencional autónomo a la indemnización por error judicial. III. ASPECTOS CONSTITUCIONALES DEL MATRIMONIO Y EL DIVORCIO CIVIL: 1. El matrimonio no inhibe los derechos derivados de uniones de hecho. 2. El matrimonio entre personas con discapacidad intelectual. 3. El libre desarrollo de la personalidad en una situación de divorcio. IV. DERECHOS DE LA NIÑEZ: 1. Derecho a sustituir el apellido de un padre biológico por el de un padre socio-afectivo. 2. Prohibición de maltratos y agresiones físicas como práctica disciplinaria. 3. Confirmación del derecho a la guardia y custodia en comaternidad. 4. ¿̇Los niños tienen derecho de acudir a espectáculos taurinos? V. LA CONSTRUCCIÓN JURÍDICA DEL DERECHO A LA PROTECCIÓN DE LA SALUD. VI. GARANTÍA JUDICIAL DEL PROCESO DEMOCRÁTICO: 1. Ilícita ampliación del plazo de un cargo de elección popular: el caso de la "Ley Bonilla». 2. Revisión de constitucionalidad de la materia de consulta popular 1/2020. VII. CONSIDERACIÓN CONCLUSIVA. BIBLIOGRAFía.

1 Profesor del Posgrado en Derecho de las Universidades Panamericana e Iberoamericana (Ciudad de México). Jefe de la Unidad Académica de la Escuela Judicial del Tribunal Electoral del Poder Judicial de la Federación. 


\section{INTRODUCCIÓN}

El 2020, año de la pandemia mundial por el coronavirus, significó un profundo impacto para el trabajo judicial en México, como en la gran mayoría de los países del orbe. La Suprema Corte dejó de sesionar durante casi 4 semanas, entre el 18 de marzo y el 19 de abril. Después del 20 de abril, hasta la conclusión del año judicial, solo celebró sesiones públicas en directo por vía remota.

Resulta de interés mencionar que, debido a que se trata de un tribunal de última instancia y a que durante el tiempo pandémico no se produjeron ordenamientos cuyo control actualizara su competencia, la Corte no tomó decisiones relevantes relacionadas con la contingencia sanitaria.

Desde el punto de vista político, la falta de declaración de emergencia pudo observarse como una estrategia gubernamental: permitió evadir el control judicial de las decisiones presidenciales sobre un estado excepcional de facto provocado por la propagación de la COVID-19. Un decreto presidencial de excepción por este motivo habría significado el inmediato control exofficio de dicho decreto por la Suprema Corte, de conformidad con el art. 29 de la Constitución. Este escenario institucional no pudo materializarse porque el presidente de la República decidió no formalizar su facultad para declarar el estado de emergencia pese al evidente impacto extraordinario de la contingencia sanitaria para la vida pública, política, social, judicial y económica del país ${ }^{2}$.

La impugnación de la normativa administrativa que, en su lugar, produjeron las autoridades de salud, que ordenaron la suspensión de actividades esenciales, se desarrolló principalmente mediante juicios de amparo ante jueces de distrito. Es previsible que durante el 2021 la Corte, a través de revisiones de amparo (segunda instancia que en la actualidad solo procede si se justifica un interés constitucional excepcional) resuelva cuestiones relativas a la contingencia y sus graves efectos, inclusive las que especialmente han afectado a sectores sociales vulnerables.

Con todo, como se revelará en esta crónica, en el 2020 la Corte sí emitió criterios de no menor importancia para el sistema de derechos humanos y el régimen democrático mexicano ${ }^{3}$.

\section{IMPLEMENTACIÓN DEL DERECHO INTERNACIONAL DE LOS DERECHOS HUMANOS}

\section{RECEPCIÓN JURISDICCIONAL DEL CASO GARCÍA CRUZ Y SÁNCHEZ SILVESTRE VS. MÉXICO}

Destacan un par de casos significativos para explicar la continuidad del proceso de interiorización de los instrumentos internacionales de derechos

\footnotetext{
Sobre este punto crítico, he realizado un análisis más amplio en: Herrera García (2020a).

3 Algunos casos que aquí destaco coinciden con la selección que realizamos en Spigno, Rivera León y Herrera García (2021).
} 
humanos en el sistema jurídico mexicano. El primero de ellos es el «expediente varios 1107/2019» que materializó la recepción de la sentencia de la Corte Interamericana en el caso García Cruz y Sánchez Silvestre vs. México, de 26 de noviembre de 2013.

La sentencia condenatoria de la Corte Interamericana de Derechos Humanos había determinado que el Estado mexicano violó derechos de los señores Juan García Cruz y Santiago Sánchez Silvestre ${ }^{4}$. Estas personas habían sido procesadas penalmente por diversos delitos con base en declaraciones obtenidas mediante tortura, las cuales, por tanto, debieron excluirse del juicio. Por ello, la Corte Interamericana condenó a México a eliminar los antecedentes penales de estas personas, entre otras medidas de reparación.

Como en otras ocasiones en las que se analizaron expedientes «varios» de cara a sentencias interamericanas condenatorias ${ }^{5}$, la Suprema Corte de México debía definir el alcance de su propio pronunciamiento frente a la implementación de la sentencia internacional y el grado de vinculatoriedad que debía atribuirse a dicha sentencia.

La Corte mexicana volvió a definir que el objeto del expediente debía limitarse a determinar cuáles eran las obligaciones del Poder Judicial de la Federación en el cumplimiento de las medidas reparatorias. También determinó que la sentencia internacional debía cumplirse «en sus términos». Así, en estos puntos, la decisión es análoga a la emitida en el importante expediente varios 912/2010 (Radilla Pacheco), del 16 de julio de 2011.

En esa tesitura, determinó la Corte, no resultaba necesaria una orden judicial adicional que tuviera que ser expedida por algún tribunal mexicano. Esa orden ya había sido definida por la Corte Interamericana en su sentencia. La decisión internacional se consideró entonces jurídicamente suficiente para producir el efecto anulatorio de los antecedentes penales de las víctimas ${ }^{6}$.

\section{DERECHO CONVENCIONAL AUTÓNOMO A LA INDEMNIZACIÓN POR ERROR JUDICIAL}

En el segundo caso, la Suprema Corte consideró que la Convención Americana sobre Derechos Humanos era el fundamento jurídico autónomo del alegado derecho a una indemnización por error judicial.

En un juicio ordinario civil, una persona demandó al gobierno de la Ciudad de México una indemnización por error judicial con base en el art. 10 de la

4 La Corte Interamericana reservó los nombres verdaderos de las víctimas para proteger su integridad y seguridad personal.

5 Para un recuento de la evolución de esta temática en la jurisprudencia constitucional, véase Herrera García (2020b).

6 Expediente varios 1107/2019, del 11 de febrero de 2020. Ponente: Juan Luis González Alcántara Carrancá. 
Convención Americana. La demandante había sido condenada por el delito de homicidio a partir de una indebida valoración probatoria. Esta circunstancia fue constatada por un tribunal federal (colegiado de circuito) que resolvió el juicio de amparo. En este juicio, ordenó la absolución de la demandante.

En un posterior juicio de amparo derivado de este caso, la demandante alegaba la violación de su derecho a una indemnización por error judicial. Esta vez, el tribunal federal negó el amparo porque consideró que el art. 109 de la Constitución prevé la responsabilidad patrimonial del Estado por motivo de actividad administrativa irregular, pero no de una jurisdiccional ${ }^{7}$. Concluyó que se trataba de una restricción constitucional expresa al derecho consagrado en el art. 10 de la Convención.

En el recurso de revisión, la Suprema Corte consideró que esa interpretación estaba equivocada. Concluyó que la imprevisión constitucional de la alegada indemnización no debía entenderse como una restricción expresa al derecho a una indemnización por error judicial cuando (como en el caso) se trata de una condena mediante sentencia firme. Recordó que no existe jerarquía normativa entre los derechos constitucionales y convencionales, por lo cual debe entenderse que el fundamento directo e inmediato de ese derecho es el art. 10 de la Convención.

Pese a la importancia del estándar referido, en el caso concreto no pudo tener entera aplicación porque no se actualizaba el supuesto de una «sentencia firme», lo cual es un requisito establecido en el art. 10 del tratado interamericano $^{8}$. En realidad, la sentencia se había revocado en el juicio de amparo en el que se ordenó la absolución del sentenciado?.

\section{ASPECTOS CONSTITUCIONALES DEL MATRIMONIO Y EL DIVORCIO CIVIL}

\section{EL MATRIMONIO NO INHIBE LOS DERECHOS DERIVADOS DE UNIONES DE HECHO}

En los últimos años, el matrimonio ha sido una institución que ha experimentado una profunda transformación jurídica como consecuencia de su

7 El art. 109, último párrafo, de la Constitución mexicana dispone lo siguiente: «La responsabilidad del Estado por los daños que, con motivo de su actividad administrativa irregular, cause en los bienes o derechos de los particulares, será objetiva y directa. Los particulares tendrán derecho a una indemnización conforme a las bases, límites y procedimientos que establezcan las leyes».

8 Cfr. Antkowiak (2019).

9 Amparo directo en revisión 3584/2017, del 22 de junio de 2020. Ponente: Jorge Mario Pardo Rebolledo. 
adecuación conceptual a un marco genuino de derechos humanos, del cual históricamente carecía. Enseguida se hará referencia a los casos que dieron continuidad a esa reconfiguración.

Una mujer demandó a un hombre por el pago de una pensión alimenticia y probó que mantenían una relación de concubinato. Este derecho le fue negado en el juicio familiar porque el hombre estaba casado con otra mujer.

El art. 65 del Código Familiar del estado de Morelos establecía que el concubinato consiste en la relación en la cual dos personas están libres del matrimonio y sin impedimento para contraerlo.

La Primera Sala declaró que ese precepto violaba el derecho a la igualdad y a la no discriminación. Para la Corte, ese requisito no tiene un fin constitucionalmente válido cuando una de las personas en la relación de hecho al mismo tiempo mantiene una relación matrimonial. El concepto legal excluye a estas personas del acceso al concubinato. Por tanto, las descarta de los derechos que derivan del concubinato, como el derecho a los alimentos.

Sin embargo, en la realidad social mexicana no debe considerarse imposible la coexistencia del concubinato y el matrimonio. La ley no puede privilegiar solamente un modo de convivencia en pareja y reconocer consecuencias jurídicas solo al matrimonio. Negar el reconocimiento de una relación de concubinato, debido a su definición legal restrictiva, implica negar el reconocimiento jurídico de una relación entre dos personas en ejercicio del libre desarrollo de su vida personal.

En consecuencia, el requisito legal restrictivo no puede justificarse con la supuesta protección de la familia o de la estabilidad de la pareja. Esta conclusión provocaría una consecuencia negativa: desproteger a la familia que se formó con motivo de una pareja de hecho ${ }^{10}$.

\section{EL MATRIMONIO ENTRE PERSONAS CON DISCAPACIDAD INTELECTUAL}

El art. 153 del Código Civil del Estado de Guanajuato prohibía que las personas con discapacidad intelectual contrajeran matrimonio. La Corte consideró que estas personas tienen derecho a contar con los apoyos y las salvaguardas necesarias para acceder a todos los derechos en igualdad de condiciones que las demás. Así, declaró la inconstitucionalidad de la prohibición porque no respetaba el derecho de las personas con discapacidad a casarse y a formar una familia, con lo cual cercenaba su derecho a la no discriminación, a ejercer su libre voluntad y su propia opinión, además de incurrir en una reducción objetiva de su libertad.

Adicionalmente, se declaró la invalidez del art. 503 del mismo Código que establecía que las personas con discapacidad intelectual tienen «incapacidad

10 Amparo directo en revisión 3727/2018, del 2 de septiembre de 2020. Ponente: Alfredo Gutiérrez Ortiz Mena. 
jurídica» y que, por ello, sus decisiones no tienen efectos en el mundo del derecho. Este precepto se declaró inconstitucional por violatorio del derecho a la igualdad y del modelo social al que se refiere la Convención sobre los Derechos de las Personas con Discapacidad ${ }^{11}$.

\section{EL LIBRE DESARROLLO DE LA PERSONALIDAD EN UNA SITUACIÓN DE DIVORCIO}

Un par de casos son relevantes en esta temática: uno relacionado con la indebida extemporaneidad de la solicitud de divorcio sin causa y otro vinculado con el plazo que condicionaba el ejercicio del derecho a contraer un nuevo matrimonio.

El art. 1126 del Código de Procedimientos Civiles para el Estado de Nuevo León establecía un supuesto problemático para el derecho a elegir mantenerse en una relación matrimonial. Establecía que, transcurridos 30 días desde la solicitud de un divorcio incausado, si no se hubiere conseguido el emplazamiento del cónyuge demandado, debía dejarse sin efectos tal solicitud y archivarse el asunto.

La Primera Sala utilizó este caso para afianzar su ya abundante doctrina sobre el libre desarrollo de la personalidad en torno a la relación matrimonial. Sostuvo que la medida legislativa vulneraba el derecho de acceso a la jurisdicción para buscar la disolución del matrimonio y el derecho a la libre determinación de un plan de vida privada. El propósito de la norma, consistente en configurar un divorcio ágil y breve, no resultaba idóneo: lejos de proporcionar un acceso efectivo a la justicia, constituía un obstáculo para el ejercicio de los derechos y para la expedita procuración del procedimiento.

Por otro lado, la medida legislativa no se justificaba adecuadamente porque la carga procesal a la que se refería la norma no podía siempre atribuírsele a la parte actora. La falta de emplazamiento también puede causarse por inactividad judicial. Además, dejar sin efectos la solicitud de divorcio es una consecuencia jurídica que, de nuevo, solo afecta a la parte actora. Resulta inútil para procurar que los funcionarios judiciales realicen con brevedad y celeridad el emplazamiento. Por lo tanto, la medida era inconstitucional por notoriamente desproporcionada ${ }^{12}$.

En esa lógica de consideraciones, la Corte resolvió otro asunto, esta vez en un control abstracto de normas, relacionado con el plazo legal que debía respetarse antes de volver a ejercer el derecho a contraer matrimonio. El Código Civil del estado de Jalisco establecía como requisito, para que las personas divorciadas pudieran contraer nuevamente matrimonio, que hubiere transcurrido un año desde la disolución del vínculo matrimonial anterior.

11 Acción de inconstitucionalidad 90/2018, del 30 de enero de 2020. Ponente: Alberto Pérez Dayán.

12 Amparo directo en revisión 5420/2018, del 26 de agosto de 2020. Ponente: Alfredo Gutiérrez Ortiz Mena. 
En un análisis basado en un test de proporcionalidad, la Corte consideró que la medida legislativa restrictiva sí perseguía un fin legítimo: la protección de la unidad familiar, los derechos de terceros y el orden público. Pero no resultaba idónea ni adecuada para alcanzar dicho objetivo al interferir indebidamente en el libre desarrollo de la personalidad.

Así, concluyó que la disposición jurídica vulneró ese derecho, el cual debe permitir a los individuos su autodeterminación en la elección de su proyecto de vida. Este derecho incluye la libre decisión de volverse a casar, pero también la libre elección del momento en que las personas pueden hacerlo a partir de que se encuentren jurídicamente libres de un matrimonio previo ${ }^{13}$.

\section{DERECHOS DE LA NIÑEZ}

\section{DERECHO A SUSTITUIR EL APELLIDO DE UN PADRE BIOLÓGICO POR EL DE UN PADRE SOCIO-AFECTIVO}

El padre biológico de una niña dejó de convivir con ella durante cinco años. Su madre contrajo matrimonio con otro hombre, con quien la niña desarrolló una relación socio-afectiva. De esta pareja, posteriormente nació un niño, quien adquirió el apellido de su padre y de la madre de ambos niños. Después de varios años de convivencia familiar, la niña quiso cambiar el apellido de su padre biológico para adoptar el apellido de padre afectivo, conforme a su nuevo entorno familiar y social.

El caso llegó a la Primera Sala. La Sala determinó que modificar el apellido del padre biológico de la niña no afectaba a su filiación cuando pretende tener el apellido de una persona con la que realmente convive en el seno familiar. Ello, aun cuando no tenga ningún vínculo biológico o jurídico con dicha persona.

El derecho al nombre implica la posibilidad de modificarlo con el propósito de ajustarlo a la realidad social y familiar de un niño, así como a la forma en que el niño se concibe a sí mismo. Reconocer la paternidad socio-afectiva en el apellido de un niño no implica restar importancia al vínculo biológico, ni a la filiación jurídica.

Este caso destacó el concepto de «familias ensambladas». Se trata de familias construidas a partir de la convivencia familiar posterior a la disolución de un vínculo familiar anterior. Los hijos nacidos en el contexto familiar original deben encontrarse protegidos y educados dentro del nuevo contexto familiar. En la nueva familia, sus miembros comparten la vida en común con cierta estabilidad, publicidad y reconocimiento. Lo cual no puede ser indiferente para el derecho.

13 Acción de inconstitucionalidad 113/2018, de 18 de junio de 2020. Ponente: Norma Lucía Piña Hernández. 
La Sala concedió el amparo para que se reconociera el derecho de la niña a su identidad, al nombre y a emitir su opinión ${ }^{14}$.

\section{PROHIBICIÓN DE MALTRATOS Y AGRESIONES FÍSICAS COMO PRÁCTICA DISCIPLINARIA}

El padre y la abuela paterna de un niño que asistía a un jardín de niños denunciaron penalmente a su madre con motivo de golpes que recibió para supuestamente corregir su conducta. A partir de ese hecho, se desencadenó un juicio ordinario del orden familiar que desembocó en un amparo directo en revisión ante la Primera Sala.

La Sala analizó la constitucionalidad del maltrato físico contra menores de edad. Consideró que los maltratos causantes de dolor o malestar, de carácter leve, moderado o grave, así como cualquier castigo que busque menospreciar, humillar, denigrar, amenazar, asustar o ridiculizar a un niño, constituye un castigo corporal ilegítimo, así como un trato cruel y degradante.

Recordó que el art. $4^{\circ}$ de la Constitución mexicana reconoce el derecho de los niños a un desarrollo sano e integral. En relación con ello, el art. 13 de la Ley General de los Derechos de Niñas, Niños y Adolescentes consagra los derechos de los menores de edad a vivir en condiciones de bienestar, a un sano desarrollo, a la integridad personal y a vivir una vida libre de violencia.

Consideró que los maltratos como pretendidos métodos correctivos o de disciplina son incompatibles con la dignidad y los referidos derechos. En ese sentido, la Sala hace un llamado en su sentencia a la erradicación del castigo corporal y los tratos crueles y degradantes, lo que además califica como una necesidad apremiante en la sociedad mexicana. Lo anterior implica también un llamado a no justificar esas conductas de los padres, tutores u otros miembros de la familia, y a no considerar los maltratos como método correctivo o de disciplina para los niños.

La Sala también reconoció que en México la problemática del castigo corporal y los tratos crueles y degradantes a niñas, niños y adolescentes se ha normalizado tradicional e históricamente, y que se ha aceptado en los ámbitos familiares, o en otros, como los educativos o en la readaptación social de la infancia. Consideró que esa arraigada situación ha tenido consecuencias directas en la forma de asimilar socialmente la violencia que se vive en el país. Por ello, confirmó que es apremiante la necesidad de erradicar los maltratos como formas de disciplina infantil ${ }^{15}$.

14 Amparo directo en revisión 6071/2018, del 25 de noviembre de 2020. Ponente: Alfredo Gutiérrez Ortiz Mena.

15 Amparo directo en revisión 8577/2019, del 3 de junio de 2020. Ponente: Norma Lucía Piña Hernández. 


\section{CONFIRMACIÓN DEL DERECHO A LA GUARDIA Y CUSTODIA EN COMATERNIDAD}

El derecho a la guardia y custodia de la niñez en el contexto de una familia homoparental fue analizado de nueva cuenta por la Primera Sala. En el caso en cuestión se presentaba una problemática particular: implicaba el análisis comparativo entre la filiación biológica y la filiación por voluntad procreacional en un escenario en el que se alegaba violencia de género, en el seno de una relación de comaternidad.

En el asunto, una de las dos mujeres de la relación se había sometido a un tratamiento de inseminación artificial. Ambas mujeres habían decidido ser madres, una de ellas en su condición de madre biológica y otra reconociendo a la menor como hija. La Corte consideró que en estos casos la guarda y custodia de un menor no debe reconocerse necesaria y precisamente a la madre biológica. Ese hecho no determina la filiación.

En el caso concreto, la Corte consideró que debía tomarse en cuenta la perspectiva de género no obstante que ambas partes eran mujeres, pues ello no descarta la posibilidad de que exista violencia sexual y económica en términos de género. En cualquier caso, concluyó que en toda decisión en la que deba dilucidarse la guarda y custodia de un menor debe primar el interés superior de la infancia ${ }^{16}$.

\section{4. ¿̇LOS NIÑOS TIENEN DERECHO DE ACUDIR A ESPECTÁCULOS TAURINOS?}

En un juicio de amparo indirecto, un padre y una madre de familia demandaron la inconstitucionalidad del art. 45 de la Ley de Protección y Defensa de Derechos de Niños, Niñas y Adolescentes del estado de Baja California. Este artículo prohibía que los menores de edad asistieran a eventos o espectáculos en los que se genere «violencia extrema contra los animales» (en el caso, las corridas de toros).

En un polémico criterio, la Segunda Sala declaró la inconstitucionalidad de ese artículo y concedió el amparo. La Sala se basó en que el Congreso estatal no motivó de manera reforzada la disposición legal. Según la Sala, esta motivación legal era obligatoria porque la norma establecía una distinción basada en la edad. La edad es una categoría sospechosa de acuerdo con el art. $1^{\circ}$ de la Constitución.

Para la Sala, el legislador debió exponer argumentos sustentados en una investigación científica. Esta investigación debía demostrar que, desde un punto de vista psicológico, es efectivamente nocivo o perjudicial para un niño asistir a esta clase de eventos. La sentencia señala que no basta asociar la violencia

16 Amparo en revisión 807/2019, del 8 de julio de 2020. Ponente: Jorge Mario Pardo Rebolledo. 
contra los animales con la afectación a menores si ello no se acredita con prueba científica. Además, esa prohibición afecta la libre decisión de los padres sobre la dirección, guía y orientación educativa de sus hijos. Lo cual, a juicio de la Sala, tiene relación con los valores, convicciones, tradiciones culturales y familiares, así como con el derecho de los niños al libre pensamiento y conciencia ${ }^{17}$.

\section{LA CONSTRUCCIÓN JURÍDICA DEL DERECHO A LA PROTECCIÓN DE LA SALUD}

El derecho a la protección de la salud cuenta con una importante y creciente presencia en la jurisprudencia de la Suprema Corte. Este año destaca un caso relacionado con el derecho a la protección de la salud de personas con VIH/ sida. Dos pacientes con virus de inmunodeficiencia humana, síndrome de inmunodeficiencia adquirida, reclamaron la falta de suministro ininterrumpido de medicamentos antirretrovirales para el tratamiento de su enfermedad. Los pacientes habían solicitado esos medicamentos a un hospital regional perteneciente al Instituto Mexicano del Seguro Social, en la ciudad de Querétaro.

Los pacientes promovieron juicios de amparo en contra de esa omisión de la autoridad sanitaria. Las demandas de amparo fueron rechazadas por el juez federal porque supuestamente no probaron dicha omisión. En contra de esa decisión, los promoventes interpusieron recursos de revisión ante la Suprema Corte.

La Primera Sala determinó que el hospital no proporcionó a los pacientes su tratamiento antirretroviral sin interrupciones, lo cual violó su derecho humano a la salud en relación con su derecho a la vida e integridad personal. Este derecho debe caracterizarse por estándares como la disponibilidad, accesibilidad, aceptabilidad y calidad.

Se estableció que la omisión de proveer el tratamiento médico constituyó el incumplimiento de la obligación del Estado: avanzar lo más rápido posible en la realización efectiva del derecho a la salud, con el máximo de los recursos disponibles. En este caso, el Estado no demostró que había adoptado las medidas necesarias para evitar el incumplimiento. Tampoco probó que había agotado todos los recursos a su alcance para garantizar el derecho. No consideró la especial protección que merecen las personas con VIH/sida.

La Sala concedió el amparo en virtud de lo cual ordenó al hospital proveer de forma oportuna, permanente y constante a los derechohabientes, sin interrupciones, los medicamentos para su tratamiento antirretroviral ${ }^{18}$.

17 Amparo en revisión 329/2020, del 25 de noviembre de 2020. Ponente: Yasmín Esquivel Mossa.

18 Amparos en revisión 226/2020 y 227/2020, del 11 de noviembre de 2020. Ponentes: Juan Luis González Alcántara Carrancá y Ana Margarita Ríos Farjat, respectivamente. 


\section{GARANTÍA JUDICIAL DEL PROCESO DEMOCRÁTICO}

\section{ILÍCITA AMPLIACIÓN DEL PLAZO DE UN CARGO DE ELECCIÓN POPULAR: EL CASO DE LA «LEY BONILLA»}

Un asunto para destacar en este apartado es el caso que fue popularmente conocido como de la «Ley Bonilla». En la acción de inconstitucionalidad 112/2019 y acumuladas la Corte determinó la inconstitucionalidad de una reforma a la Constitución del estado de Baja California porque amplió el periodo del gobernador electo de esa entidad federativa de dos a cinco años. Esta decisión fue adoptada por unanimidad de 11 ministros y ministras del Pleno.

Las razones de la inconstitucionalidad fueron múltiples pues esa reforma violaba diversos principios fundamentales del sistema democrático: principios de certeza electoral, legalidad y seguridad jurídica; las bases constitucionales de la organización política de los estados; el derecho a votar y ser votado en condiciones de libertad e igualdad; así como los principios de no reelección y de irretroactividad de las leyes.

Además, dicha reforma también fue declarada inconstitucional por una cuestión formal de evidente acreditación: se había producido con posterioridad a la elección del gobernador, con lo cual también se violó el art. 105 de la Constitución que señala que las leyes electorales deben publicarse noventa días antes de iniciar el proceso electoral y que no puede haber modificaciones fundamentales durante el propio proceso. Con la modificación del periodo del gobernador electo una vez que había terminado el proceso electoral, el poder reformador local incurrió en fraude al mandato de la Constitución federal ${ }^{19}$.

\section{REVISIÓN DE CONSTITUCIONALIDAD DE LA MATERIA DE CONSULTA POPULAR $1 / 2020$}

El presidente Andrés Manuel López Obrador, en uso de sus atribuciones constitucionales, propuso realizar una polémica consulta popular. El art. 35 de la Constitución dispone que la Suprema Corte debe analizar la constitucionalidad de la materia de estas consultas. La pregunta que el presidente quería proponer era la siguiente: « Está de acuerdo o no con que las autoridades competentes, con apego a las leyes y procedimientos aplicables, investiguen, y en su caso sancionen, la presunta comisión de delitos por parte de los expresidentes Carlos Salinas de Gortari, Ernesto Zedillo Ponce de León, Vicente Fox Quesada, Felipe Calderón

19 Acción de inconstitucionalidad 112/2019 y sus acumuladas 113/2019, 114/2019, 115/2019, 119/2019 y 120/2019, del 11 de mayo de 2020. Ponente: Fernando Franco González Salas. Para una interesante aproximación al caso de la «Ley Bonilla» desde las teorías de la democracia, véase Niembro Ortega (2021). 
Hinojosa y Enrique Peña Nieto antes, durante y después de sus respectivas gestiones?».

La decisión de la Corte fue motivo de gran deliberación en la comunidad jurídica, entre otras cosas porque la Constitución es explícita en el sentido de prohibir consultas populares sobre restricciones a derechos humanos.

La Corte dividió su estudio en dos partes: el análisis de constitucionalidad de la materia de la consulta y el análisis de legalidad de la pregunta. Con respecto a la primera cuestión, con una votación de 6 contra 5, determinó que la materia de la consulta sí era constitucional. A su juicio, la materia debía interpretarse como una pretensión de consultar a la ciudadanía sobre un proceso de esclarecimiento de decisiones políticas tomadas en años pasados. Ello, con la supuesta finalidad de garantizar la justicia y los derechos de las víctimas.

En cambio, con respecto a la segunda cuestión, decidió que la pregunta no era legal porque no tenía lenguaje neutro y contenía juicios de valor. Por lo tanto, con base en la facultad que le reconoce el art. 26 de la Ley Federal de Consulta Popular, la Corte modificó la pregunta. En su lugar, redactó la siguiente: "¿Estás de acuerdo o no en que lleven a cabo las acciones pertinentes, con apego al marco constitucional y legal, para emprender un proceso de esclarecimiento de las decisiones políticas tomadas en los años pasados por los actores políticos, encaminado a garantizar la justicia y los derechos de las posibles víctimas?». Esta consulta popular tuvo lugar el domingo 1 de agosto de 2021, por cierto, con desalentadores resultados de participación ciudadana, que equivalió a un 7,11\% de la lista nominal de electores.

Este asunto puede resultar un parteaguas en la conducta que despliegue la Corte de cara a numerosas políticas públicas y legislativas dudosamente constitucionales y que aún no han sido motivo de resolución en el presente periodo presidencial. O puede mantenerse como un episodio anecdótico de cara al trabajo que le espera. En todo caso, ha quedado registrado como un caso emblemático en tiempos de la denominada por el actual presidente de la República como «cuarta transformación» de la vida pública de México $^{20}$.

\section{CONSIDERACIÓN CONCLUSIVA}

El 2020 significó una nueva oportunidad para la consolidación de ciertas líneas ascendentes en la configuración jurisprudencial de derechos fundamentales. Como se muestra en esta crónica, es el caso del derecho al libre desarrollo de la personalidad, derechos humanos de las mujeres en problemáticas familiares,

20 Revisión de constitucionalidad de la materia de consulta popular 1/2020, del 1 de octubre de 2020. Ponente: Luis María Aguilar Morales. Para Pedro Salazar la decisión de la Corte en este caso constituyó «una derrota del derecho por las razones y lógicas del poder», cfr. Salazar Ugarte (2021). 
derechos de la niñez, el derecho a la protección de la salud de personas en condición de vulnerabilidad, así como los derechos políticos relacionados con el fraude a la Constitución en el que (de acuerdo con la propia Corte) incurrió la «Ley Bonilla». Por supuesto, en contraste, este año también será recordado por la problemática decisión relativa a la consulta popular 1/2020. En mi opinión, este caso dio lugar a una de las peores resoluciones de la historia reciente de la Corte en términos de racionalidad jurídica, que es el único baremo legítimo en todo análisis del trabajo judicial.

En el transcurso del 2021, la Suprema Corte se encuentra inmersa en un proceso de transición con motivo de la reforma constitucional de este año en materia judicial, que incide en su régimen competencial ${ }^{21}$. La reforma introduce la noción del amparo directo en revisión como recurso que resulta solo procedente por interés constitucional excepcional. En ese sentido, en principio, proporciona un mejor fundamento para aproximarse a un esquema de writ of certiorari. La reforma también introduce la inimpugnabilidad del desechamiento de dicho recurso, que antes podía reclamarse ante la propia Corte.

Finalmente, la reforma instaura una regla de precedentes obligatorios con una sola decisión por mayorías calificadas, en Pleno (8 de 11) y Salas (4 de 5). Este novedoso sistema sustituye al preconstitucional de la reiteración, que tuvo aplicabilidad en México por más de 140 años $^{22}$. En todo caso, está por verse la forma en que estas nuevas disposiciones constitucionales y legales tendrán algún impacto, y en qué medida, en el papel del más alto tribunal en el azaroso proceso democrático del país. Seguramente será un aspecto que merecerá una especial consideración en la crónica del próximo año.

\section{Bibliografía}

Antkowiak, Th. (2019). Artículo 10. Derecho a indemnización. En Ch. Steiner y M. C. Fuchs (eds.). Convención Americana sobre Derechos Humanos. Comentario (pp. 341-348). Bogotá; Berlín: Fundación Konrad Adenauer.

Caballero Juárez, J. A. (2021). La reforma judicial de 2021. ¿Hacia dónde va la justicia? México: Instituto de Investigaciones Jurídicas; Universidad Nacional Autónoma de México.

Herrera García, A. (2020a). ¿Ineficacia por omisión? El problema constitucional ante la emergencia pandémica en el caso mexicano. En C. Landa (coord.). Constitución y emergencia sanitaria (vol. 2) (pp. 79-89). Lima: Palestra.

21 Esta reforma constitucional se publicó en el Diario Oficial de la Federación el 11 de marzo de 2021.

22 Formulé un apunte crítico sobre la modificación relacionada con la lógica del precedente judicial en: Herrera García (2021). Para un análisis crítico sobre la reforma judicial en su generalidad, véase Caballero (2021). 
- (2020b). Sentencias de la Corte Interamericana de Derechos Humanos en contra del Estado mexicano. El papel de la Suprema Corte en la búsqueda de su cumplimiento. En V. Bazán y M. C. Fuchs (eds.). Ejecución, nivel de cumplimiento e implementación de sentencias de tribunales constitucionales y cortes supremas en la región (pp. 201-222). Bogotá; Berlín: Tirant lo Blanch, Fundación Konrad Adenauer.

- (2021). Más allá del transitorio: ¿El precedente judicial consolida a la justicia constitucional mexicana? IberICONnect. Revista Internacional de Derecho Constitucional [blog], 6-10-2021. Disponible en: https://bit.ly/3pHiA3n.

Niembro Ortega, R. (2021). La argumentación constitucional de la Suprema Corte. A diez años de la reforma de derechos humanos. México: Instituto de Investigaciones Jurídicas.

Salazar Ugarte, P. (2021). El poder sobre el derecho. El caso de la consulta popular para juzgar a los expresidentes. México: Instituto de Investigaciones Jurídicas.

Spigno, I., Rivera León, M. A. y Herrera García, A. (2021). México. En R. Albert, D. Landau, P. Faraguna y S. Drugda (eds.). 2020 Global Review of Constitutional Law (pp. 192-196). Chestnut Hill, Massachusetts: I-CONect. 